\title{
openheart Blood pressure target achievement and antihypertensive medication use in women and men after first-ever myocardial infarction: the Tromsø Study 1994-2016
}

\author{
Laila A Hopstock, ${ }^{1}$ Anne Elise Eggen, ${ }^{2}$ Maja-Lisa Løchen, ${ }^{2,3}$ Ellisiv B Mathiesen, ${ }^{4,5}$ \\ Amalie Nilsen, ${ }^{6}$ Inger Njølstad, ${ }^{2}$ Tom Wilsgaard ${ }^{2}$
}

\begin{abstract}
- Additional material is published online only. To view please visit the journal online (http://dx.doi.org/10.1136/ bmjres-2017-000203).
\end{abstract}

To cite: Hopstock LA, Eggen AE, Løchen M-L, et al. Blood pressure target achievement and antihypertensive medication use in women and men after first-ever myocardial infarction: the Tromsø Study 1994-2016. Open Heart 2018;5:e000746. doi:10.1136/

openhrt-2017-000746

Received 6 November 2017 Revised 8 December 2017 Accepted 11 December 2017

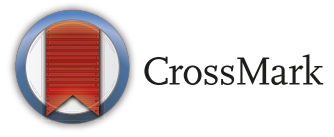

For numbered affiliations see end of article.

Correspondence to Dr Laila A Hopstock; laila. hopstock@uit.no

\section{ABSTRACT}

Background Recurrent cardiovascular events after myocardial infarction (MI) are frequent, and gender differences in blood pressure treatment have been reported. Despite increased focus on secondary prevention, recent reports indicate that treatment targets are not achieved. There is a need for gender-specific analyses of post-Ml blood pressure treatment target achievement and antihypertensive medication adherence. Design We investigated the change in systolic and diastolic blood pressure and antihypertensive drug use after first-ever Ml over two time periods in a Norwegian population-based study.

Methods We followed 10089 participants (55\% women) attending the Troms $\emptyset$ Study in 1994-1995 (Ml-cohort I) and 8412 participants (55\% women) attending the Troms $\emptyset$ Study 2007-2008 (Ml-cohort II) for first-ever Ml up to their participation in 2007-2008 and 2015-2016, respectively. We used linear regression models to investigate sex and age differences in change in blood pressure.

Results A total of 396 participants in Ml-cohort I and 131 participants in Ml-cohort II had a first-ever MI in the observation periods. In Ml-cohort I, 35\% of the women and $52 \%$ of the men achieved the treatment targets of blood pressure $<140 / 90 \mathrm{~mm} \mathrm{Hg}(130 / 80 \mathrm{~mm} \mathrm{Hg}$ if diabetic), while the proportions for Ml-cohort II were $50 \%$ and $54 \%$ for women and men, respectively. Antihypertensive use was reported in $88 \%$ of women and $87 \%$ of men in Mlcohort I, and $76 \%$ of women and $81 \%$ of men in MI-cohort II.

Conclusions We found an overall low achievement of the treatment target. The findings call for better strategies for secondary prevention for both women and men.

\section{INTRODUCTION}

Lifestyle changes and treatment adherence after acute myocardial infarction (MI) are associated with improved prognosis and lower mortality ${ }^{1}$; however, secondary prevention is still inadequate in many European countries, and the majority of MI patients do not achieve treatment goals. ${ }^{2}$ In Norway,

\section{Key messages}

What is already known about this subject?

- Secondary prevention guidelines for myocardial infarction patient care are gender neutral, but recent studies from European countries show that women were less likely to achieve treatment goals compared with men.

What does this study add?

- Gender-specific analysis of achievement of blood pressure treatment target and antihypertensive medication use after myocardial infarction in a Norwegian general population.

How might this impact on clinical practice?

- Treatment target achievement is low in both women and men, and better strategies for secondary prevention are needed.

cardiovascular diseases (CVD) are the most common cause of inpatient hospitalisation. ${ }^{3}$ Long-standing decrease in MI case fatality over four decades, ${ }^{4}$ currently as low as $10 \%,{ }^{5}$ leads to increase in the proportion of patients living with coronary heart disease complications. ${ }^{6}$ One of four acute MI hospitalisations are recurrent events, despite that $>90 \%$ of all Norwegian MI patients are prescribed medical treatment such as antihypertensive drugs at hospital discharge ${ }^{7}$ in accordance with European guidelines. The need for more intensive management of MI patients has previously been highlighted. ${ }^{8-11}$ Secondary prevention guidelines are gender neutral, and post-MI medications such as antihypertensive drug use have shown similar protection against CVD events in men and women. ${ }^{12}$ However, a recently published study from the SWEDEHEART registry ${ }^{13}$ showed that Swedish women were less likely to achieve treatment 
goals for blood pressure, and a smaller proportion were on beta-blocker or ACE-inhibitor treatment compared with Swedish men. There is a need for gender-specific analysis of post-MI achievement of blood pressure treatment target and antihypertensive medication adherence in the Norwegian population.

\section{AIM}

We investigated the change in systolic and diastolic blood pressure levels and prevalence of antihypertensive drug use after MI among women and men in a Norwegian prospective cohort study followed in two time periods.

\section{METHODS \\ Study population}

The Troms $\varnothing$ Study $^{9}$ is an ongoing population-based cohort study in the municipality of Troms $\varnothing$, Northern Norway. The study includes seven waves of data collection (Tromsø 1: 1974; Tromsø 2: 1979-1980; Tromsø 3: 1986-1987; Tromsø 4: 1994-1995; Tromsø 5: 2001-2002; Tromsø 6: 2007-2008; Tromsø 7: 2015-2016) to which total birth cohorts and representative population samples were invited. Response rates were between $65 \%$ and $79 \%$. A total of 45473 women and men have participated in one or more waves of the study. The participants have given written informed consent.

The present analyses include two cohorts. This allows comparison with coinciding EUROASPIRE studies from the same time periods. The basis for the first cohort were all Troms $\varnothing 4$ participants with no prevalent MI aged 25-74 in 1994 ( $\mathrm{n}=24984)$, of whom 10154 also attended Troms $\varnothing 6$ and formed cohort I. The basis for the second cohort were all Troms $\varnothing 6$ participants with no prevalent MI aged 32-87 years in 2007 ( $\mathrm{n}=12358)$, and 8604 of these also attended Troms $\varnothing 7$ and formed cohort II. We excluded subjects who did not consent to research $(\mathrm{n}=1)$ or did not have valid blood pressure measurements in Troms $\varnothing$ 4-6 $(n=65)$ or Troms $\varnothing$ 6-7 $(n=61)$, leaving 10089 participants (55\% women) in cohort I with baseline 1994-1995, and 8543 participants (55\% women) in cohort II with baseline 2007-2008, to be followed for firstever MI up to the next screening in 2007-2008 or 20152016, respectively. Among these, 396 participants (33\% women) had a first-ever MI during 1994-2008 (MI-cohort I) and 131 participants ( $34 \%$ women) had a first-ever MI during 2007-2016 (MI-cohort II). To allow for change in risk factors, participants with an $\mathrm{MI}<3$ months prior to their second screening were not included MI cohort I. Due to lack of validated MI endpoints after 2013, in MI-cohort II, participants with an MI <2years before their second screening were not included in MI-cohort II. Among the 24984 participants of the original Troms $\varnothing$ 4 invited to the Troms $\varnothing$ 6, 906 experienced a first-ever MI before 2008 and survived for at least 30 days, that is, 510 participants with MI from the original cohort did not attend the second screening. Of these, $65 \%$ were not invited to Troms $\varnothing 6$ (due to emigration (13\%), mortality
$(33 \%)$ or not in the random sample invited to Troms $\varnothing 6$ $(20 \%))$. Similarly, among the 12358 participants of the original Troms $\varnothing$ 6, 235 experienced a first-ever MI before 2014 and survived for at least 30 days, that is, 104 participants with MI from the original cohort did not attend the second screening. Of these, $43 \%$ were not invited to Troms $\varnothing 7$ (due to emigration (10\%) or mortality $(33 \%)$ ). The non-attendees were older, had a higher systolic blood pressure and were more likely to be smokers than those who attended both waves (online supplementary table 1).

\section{Measurements, questionnaires and event validation}

Blood pressure was measured on the participant's right upper arm with a properly sized cuff based on arm circumference. Trained personnel performed all measurements. Blood pressure was measured three times with an oscillometric digital automatic device (in Tromsø 4: Dinamap Vital Signs Monitor; Critikon, Tampa, Florida, USA, and in Tromsø 6-7: Dinamap ProCare 300 monitor, GE Healthcare, Norway), measurements being separated by a $1 \mathrm{~min}$ interval after $2 \mathrm{~min}$ seated rest. The mean of the two final readings was used in the analysis. Antihypertensive drug use was always assessed through questionnaires and a written list of brand names of medications used on regular basis checked by health personnel at the study site (in Troms $\varnothing 4$ only in individuals aged 55-74 years). Self-report of medication used regularly for chronic conditions is considered accurate. ${ }^{10}$ Incident cases of CHD were recorded from each participant's study entry in 1994-1995 until 31 December 2008 and 2007-2008 until 31 December 2013, respectively. Adjudication of hospitalised and out-of-hospital incident MI was based on all available information including medical records from hospitals, ambulance service, general practitioners, nursing homes, autopsy reports and death certificates. Validation of each event was based on modified WHO MONICA (Multinational MONItoring of trends and determinants in CArdiovascular disease/MORGAM (MOnica Risk, Genetics, Archiving and Monograph)) criteria described elsewhere, ${ }^{14}$ and included clinical symptoms and signs, findings in ECGs, values of cardiac biomarkers and autopsy reports.

\section{Statistics}

Statistical analyses were performed using SAS V.9.4 (SAS Institute). Change in blood pressure was defined as the difference between the values in Troms $\varnothing 6$ and Troms $\varnothing 4$, and Troms $\varnothing 7$ and Troms $\varnothing 6$, respectively. Descriptive characteristics were reported with means (SD or $95 \%$ CIs) for continuous variables and proportions for binary variables. Test for differences in blood pressure between baseline (pre-MI) and second screening (post-MI) were assessed using pairwise t-tests. Multivariable linear regression models were used to test for equality in blood pressure change between women and men, age groups and different groups defined by blood pressure levels in Troms $\varnothing 6$ or Troms $\varnothing 7$, respectively, or by levels of time between MI and the participation date 
Table 1 Baseline characteristics by cohorts: the Tromsø Study 1994-2016

\begin{tabular}{|c|c|c|c|c|}
\hline \multirow[b]{2}{*}{ Characteristics } & \multicolumn{2}{|c|}{ Cohort I, 1994-2008 } & \multicolumn{2}{|c|}{ Cohort II, 2007-2016 } \\
\hline & Total cohort & MI cohort & Total cohort & MI cohort \\
\hline $\mathrm{N}$ & 10089 & 396 & 8543 & 131 \\
\hline Age (years) & $46.8(11.7)$ & $56.1(8.7)$ & $57.4(10.5)$ & $64.1(9.5)$ \\
\hline Male (\%) & $45.3(4575)$ & $67.4(267)$ & $45.3(3874)$ & $66.4(87)$ \\
\hline Total cholesterol (mmol/L) & $6.1(1.3)$ & $7.0(1.1)$ & $5.7(1.1)$ & $6.1(1.0)$ \\
\hline Low-density lipoprotein cholesterol (mmol/L) & $3.9(1.2)$ & $4.8(1.0)$ & $3.4(1.0)$ & $4.0(0.9)$ \\
\hline High-density lipoprotein cholesterol (mmol/L) & $1.5(0.4)$ & $1.4(0.4)$ & $1.5(0.4)$ & $1.4(0.3)$ \\
\hline Triglycerides (mmol/L) & $1.5(1.0)$ & $2.0(1.1)$ & $1.5(0.9)$ & $1.7(0.9)$ \\
\hline Systolic blood pressure (mm Hg) & $133(18.0)$ & $145(20.0)$ & $133(21.6)$ & $146(23.6)$ \\
\hline Diastolic blood pressure $(\mathrm{mm} \mathrm{Hg})$ & $78.1(11.6)$ & $85.6(11.4)$ & $77.6(10.5)$ & $82.5(10.6)$ \\
\hline Body mass index $\left(\mathrm{kg} / \mathrm{m}^{2}\right)$ & $25.3(3.7)$ & $26.7(3.4)$ & $26.8(4.2)$ & $27.8(4.5)$ \\
\hline Daily smoking (\%) & 33.6 (3388) & $44.2(175)$ & $17.9(1517)$ & $31.3(41)$ \\
\hline
\end{tabular}

Values are mean (SD) or per cent (number).

MI, myocardial infarction.

in Troms $\varnothing 6$ or Troms $\varnothing 7$, respectively. Linear regression models were also used to calculate age-adjusted means between different groups. Logistic regression was used to test age-adjusted gender differences in achievement of treatment targets.

\section{RESULTS}

Mean age at first MI was 67 years in women and 63 years in men in MI-cohort I and 71 years in women and 65 years in men in MI-cohort II. Differences between the total and the MI-cohort for each period are presented in table 1.

In MI-cohort I, the age-adjusted mean systolic blood pressure was 146.9 and $144.3 \mathrm{~mm} \mathrm{Hg}$ at baseline $(\mathrm{P}=0.22)$, and 147.3 and $140.2 \mathrm{~mm} \mathrm{Hg}$ at the second screening $(\mathrm{P}=0.0048)$, in women and men, respectively. The age-adjusted mean change in systolic blood pressure was $0.4(95 \%$ CI -3.7 to 4.5$) \mathrm{mm} \mathrm{Hg}$ in women and -4.1 (95\% CI -7.0 to -1.3$) \mathrm{mm} \mathrm{Hg}$ in men ( $\mathrm{P}$ value for sex difference $=0.083$ ) (table 2). In MI-cohort II, the age-adjusted mean systolic blood pressure was 146.5 and $146.5 \mathrm{~mm} \mathrm{Hg}$ at baseline $(\mathrm{P}=0.98)$, and 138.6 and $133.5 \mathrm{~mm} \mathrm{Hg}$ at the second screening $(\mathrm{P}=0.29)$, in women and men, respectively. The mean decrease in systolic blood pressure was -7.9 (95\% CI -15.5 to -0.4$) \mathrm{mm} \mathrm{Hg}$ in women and -13.0 (95\% $\mathrm{CI}-18.3$ to -7.7$) \mathrm{mm} \mathrm{Hg}$ in men (P value for sex difference $=0.28)$ (table 2).

In MI-cohort I, the age-adjusted mean diastolic blood pressure was 84.7 and 86.0 at baseline $(\mathrm{P}=0.27)$, and 75.3 and $77.4 \mathrm{~mm} \mathrm{Hg}$ at the second screening $(\mathrm{P}=0.071)$, in women and men, respectively. The age-adjusted mean decrease in diastolic blood pressure was $-9.4 \quad(95 \%$ CI -11.6 to -7.3$) \mathrm{mm} \mathrm{Hg}$ in women and -8.6 (95\% CI -10.1 to -7.1$) \mathrm{mm} \mathrm{Hg}$ in men ( $\mathrm{P}$ value for sex difference $=0.41) \quad($ table 3$)$. In MI-cohort II, the age-adjusted mean diastolic blood pressure was 78.9 and $84.3 \mathrm{~mm} \mathrm{Hg}$ at baseline $(\mathrm{P}=0.007)$, and 73.4 and $73.7 \mathrm{~mm} \mathrm{Hg}$ at the

Table 2 Systolic blood pressure levels after first-ever myocardial infarction (MI) by cohort, sex and age: the Troms $\varnothing$ Study 1994-2016

\begin{tabular}{|c|c|c|c|c|c|c|c|c|}
\hline \multirow[b]{2}{*}{ Age at MI } & \multicolumn{4}{|c|}{ MI-cohort I, 1994-2008 } & \multicolumn{4}{|c|}{ MI-cohort II, 2007-2016 } \\
\hline & $\mathbf{N}$ & 1994-1995 & 2007-2008 & Change $(95 \% \mathrm{Cl})$ & $\mathbf{N}$ & 2007-2008 & 2015-2016 & Change $(95 \% \mathrm{Cl})$ \\
\hline Overall & 396 & $145.2(20.0)$ & $142.5(24.1)$ & $-2.7(-5.0$ to -0.4$)$ & 131 & $146.5(23.6)$ & $135.2(26.1)$ & $-11.3(-15.5$ to -7.1$)$ \\
\hline$\geq 65$ years & 179 & $150.0(20.6)$ & $148.4(26.0)$ & $-1.6(-5.2$ to 2.1$)$ & 77 & $152.5(23.4)$ & $139.7(30.1)$ & $-12.9(-18.9$ to -6.8$)$ \\
\hline \multicolumn{9}{|l|}{ Women } \\
\hline Age-adjusted & 129 & $146.9(24.4)$ & $147.3(28.0)$ & $0.4(-3.7$ to 4.5$)$ & 44 & $146.5(28.4)$ & $138.6(27.8)$ & $-7.9(-15.5$ to -0.4$)$ \\
\hline \multicolumn{9}{|l|}{ Men } \\
\hline Crude & 267 & $143.3(17.3)$ & $139.0(21.2)$ & $-4.3(-6.8$ to -1.8$)$ & 87 & $144.8(20.7)$ & $132.2(24.8)$ & $-12.6(-18.2$ to -7.0$)$ \\
\hline Age-adjusted & 267 & $144.3(17.3)$ & $140.2(21.2)$ & $-4.1(-7.0$ to -1.3$)$ & 87 & $146.5(20.7)$ & $133.5(24.8)$ & $-13.0(-18.3$ to -7.7$)$ \\
\hline
\end{tabular}

Values are number, mean (SD or $95 \% \mathrm{Cl}$ ) $\mathrm{mm} \mathrm{Hg}$. 
Table 3 Diastolic blood pressure levels after first-ever myocardial infarction (MI) by cohort, sex and age: the Tromsø Study 1994-2016

\begin{tabular}{|c|c|c|c|c|c|c|c|c|}
\hline \multirow[b]{2}{*}{ Age at MI } & \multicolumn{4}{|c|}{ MI-cohort I, 1994-2008 } & \multicolumn{4}{|c|}{ MI-cohort II, 2007-2016 } \\
\hline & $\mathbf{N}$ & 1994-1995 & $2007-2008$ & Change $(95 \% \mathrm{Cl})$ & $\mathbf{N}$ & $2007-2008$ & 2015-2016 & Change $(95 \% \mathrm{Cl})$ \\
\hline Overall & 396 & $85.6(11.4)$ & $76.7(11.0)$ & $-8.9(-10.1$ to -7.6$)$ & 131 & $82.5(10.6)$ & $73.6(12.4)$ & $-8.9(-11.3$ to -6.6$)$ \\
\hline$<65$ years & 217 & $85.6(11.8)$ & $78.2(10.8)$ & $-7.3(-9.1$ to -5.6$)$ & 54 & $83.4(13.0)$ & $75.6(11.0)$ & $-7.9(-11.2$ to -4.5$)$ \\
\hline$\geq 65$ years & 179 & $85.7(10.9)$ & $74.9(11.0)$ & $-10.8(-12.5$ to -9.0$)$ & 77 & $81.9(8.60)$ & $72.2(13.2)$ & $-9.7(-13.0$ to -6.4$)$ \\
\hline \multicolumn{9}{|l|}{ Women } \\
\hline Crude & 129 & $85.2(13.0)$ & $74.8(11.8)$ & $-10.4(-12.7$ to -8.1$)$ & 44 & $79.1(9.1)$ & $72.8(10.9)$ & $-6.3(-9.7$ to -2.9$)$ \\
\hline Age-adjusted & 129 & $84.7(13.0)$ & $75.3(11.8)$ & $-9.4(-11.6$ to -7.3$)$ & 44 & $78.9(9.1)$ & 73.4 (10.9) & $-5.5(-9.7$ to -1.4$)$ \\
\hline \multicolumn{9}{|l|}{ Men } \\
\hline Crude & 267 & $85.8(10.5)$ & $77.6(10.5)$ & $-8.1(-9.6$ to -6.7$)$ & 87 & $84.2(11.0)$ & $74.0(13.1)$ & $-10.3(-13.3$ to -7.2$)$ \\
\hline Age-adjusted & 267 & $86.0(10.5)$ & $77.4(10.5)$ & $-8.6(-10.1$ to -7.1$)$ & 87 & $84.3(11.0)$ & 73.7 (13.1) & $-10.6(-13.6$ to -7.7$)$ \\
\hline
\end{tabular}

Values are number, mean (SD or $95 \% \mathrm{Cl}) \mathrm{mm} \mathrm{Hg}$.

second screening $(\mathrm{P}=0.89)$, in men and women, respectively. The mean decrease in diastolic blood pressure was $-5.5(95 \%$ CI -9.7 to -1.4$) \mathrm{mm} \mathrm{Hg}$ in women and -10.6 (95\% CI -13.6 to -7.7$) \mathrm{mm} \mathrm{Hg}$ in men (P value for sex difference $=0.056)($ table 3$)$.

In MI-cohort I, the age-adjusted prevalence of antihypertensive drug use was $11.8 \%$ in women and $8.3 \%$ in men at baseline, and $88 \%$ in women and $87 \%$ in men at the second screening. In MI-cohort II, the age-adjusted prevalence of antihypertensive drug use was $31 \%$ and $30 \%$ at baseline, and $76 \%$ and $81 \%$ at the second screening in women and men, respectively.

Table 4 shows the proportion of MI patients achieving the treatment target for prevention of recurrent events (systolic blood pressure $<140 \mathrm{~mm} \mathrm{Hg}(130 \mathrm{~mm} \mathrm{Hg}$ if diabetic) and diastolic blood pressure $<90 \mathrm{~mm} \mathrm{Hg}$ ( $80 \mathrm{~mm} \mathrm{Hg}$ if diabetic)). In MI-cohort I, the treatment target was achieved by $35 \%$ of the women compared with $52 \%$ of the men (age-adjusted $\mathrm{P}=0.046$ ). In MI-cohort II, the treatment target was achieved by $50 \%$ of the women compared with $54 \%$ of the men (age-adjusted $\mathrm{P}=0.68$ ). No consistency was found between blood pressure change and time interval between first-ever MI and second screening (online supplementary table 2-5).

\section{DISCUSSION}

In this study of MI patients from a general population followed in two study periods, we found an overall low achievement of the blood pressure treatment target, as well as some gender disparities in mean levels of blood pressure and treatment achievement.

\section{Prevalence of antihypertensive drug use and overall achievement of treatment targets}

Guidelines for control of various CVD risk factors for prevention of recurrent events have changed over time since the first Joint European Society guidelines (JESC) from $1994 .{ }^{15}$ An overall treatment target for blood pressure of $140 / 90 \mathrm{~mm} \mathrm{Hg}$ was introduced in the JESC2 publication in $1998,{ }^{16}$ with an additional treatment target of 130/80 mm Hg for very high-risk individuals (including patients with established CVD and/or diabetes) suggested from JESC3 in $2003^{17}$ and further. Although extensively discussed, these continued to be the overall treatment goals throughout this study period ${ }^{17-19}$ and further in the most recently published JESC6 from $2016 .{ }^{20}$ In the third EUROASPIRE study conducted in 2006-2007, ${ }^{21} 80 \%$ of the MI patients used beta-blockers and $71 \%$ used ACE-inhibitors or angiotensin II receptor blockers, and $44 \%$ of all MI patients reached the treatment target of $140 / 90 \mathrm{~mm} \mathrm{Hg}$ (or $130 / 80 \mathrm{~mm} \mathrm{Hg}$ for patients with diabetes). In the fourth and most recent EUROPASPIRE study from $2015,{ }^{2}$ the overall prevalence of all antihypertensive drug use was $78 \%$, and $56 \%$ of all MI patients reached the treatment target of $140 / 90 \mathrm{~mm} \mathrm{Hg}$ (or $130 / 80 \mathrm{~mm} \mathrm{Hg}$ for patients with diabetes). On average, the proportion of MI patients achieving the treatment targets and reporting use of antihypertensive drugs was similar in our two study periods and the coinciding third and fourth EUROASPIRE studies.

\section{Gender differences in secondary prevention}

The higher incidence of MI in men compared with women has resulted in less awareness of prevention and treatment in women. ${ }^{22}$ A publication from EUROASPIRE III showed that women were $63 \%$ less likely to achieve appropriate secondary prevention than men, ${ }^{23}$ and other previously published studies also show that women are less likely to use antihypertensive drugs and to achieve treatment targets for blood pressure control than men. ${ }^{132}$ In our study, there was a tendency (although not statistically significant in all analysis) towards women having higher systolic blood pressure, less decrease in blood pressure, less reported use of antihypertensives and lower achievement of the treatment targets at follow-up. Treatment guidelines do not differ by sex, and meta-analyses of the effectiveness of antihypertensive drug therapy do not report gender differences. ${ }^{12}$ Gender 


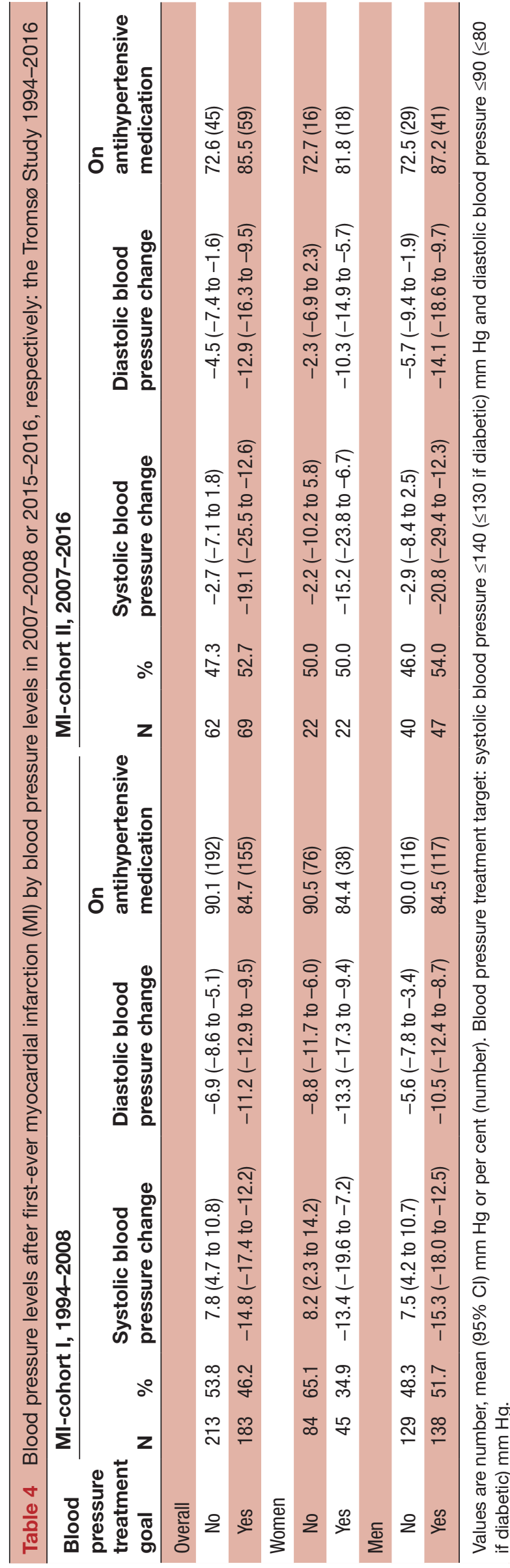

differences in antihypertensive drug use could be the result of lower initiation of treatment or lower adherence to treatment. Lower treatment initiation after MI among women compared with men has been reported in several studies. ${ }^{24}{ }^{25}$ Gender differences in adherence to antihypertensive drug use after MI show various results; some studies report women to be less adherent to antihypertensive drug use compared with men, ${ }^{24} 2627$ others do not report gender differences in antihypertensive drug adherence. ${ }^{27}$ Overall, women tend to experience MI somewhat later in life than men, and elderly MI patients are less likely to receive secondary prevention, although treatment of the elderly is highly beneficial. ${ }^{28}$ This could suggest an age-sex interaction responsible for the lower use of secondary prevention in women. ${ }^{24}{ }^{25}$ Lower initiation of antihypertensive treatment in women compared with men, and higher blood pressure at hospital discharge, has also been found in young MI patients. ${ }^{25}$

\section{Study limitations}

Only $44 \%$ and $55 \%$ of the surviving MI patients in the original cohorts attended Troms $\varnothing 6$ and Troms $\varnothing 7$, respectively. Non-responders among MI patients in the original Tromsø 4 and Tromsø 6 cohorts had higher baseline systolic blood pressure than responders. We assume that participants that did not attended Troms $\varnothing 6$ or Troms $\varnothing$ 7 , respectively, due to death, disease or other causes were more prone to have a less favourable blood pressure profile. Thus, our results can be biased towards more favourable blood pressure levels than in the average MI population. Further, no analyses of predictors for change in blood pressure or medication use were included in this study.

\section{CONCLUSION}

In this descriptive study of change in blood pressure after MI over time, we found an overall low achievement of the long-standing treatment target, consistent with previous studies. A larger proportion of women reached the treatment goals in the last study period compared with the first. However, compared with men, women had higher follow-up mean systolic blood pressure levels in the second study period. The findings call for better treatment strategies for secondary prevention in both women and men.

\section{Author affiliations}

${ }^{1}$ Department of Health and Care Sciences, UiT The Arctic University of Norway, Troms $\emptyset$, Norway

${ }^{2}$ Department of Community Medicine, UiT The Arctic University of Norway, Tromsø, Norway

${ }^{3}$ Department of Cardiology, University Hospital of North Norway, Troms $\emptyset$, Norway ${ }^{4}$ Department of Clinical Medicine, UiT The Arctic University of Norway, Troms $\emptyset$, Norway

${ }^{5}$ Department of Neurology, The University Hospital of North Norway, Troms $\emptyset$, Norway ${ }^{6}$ Department of Medicine, Nordland Hospital Trust, Bodø, Norway

Contributors LAH and TW contributed to the conception and design. TW performed the data analysis. LAH drafted the manuscript. AEE, M-LL, EBM, AN, IN and TW critically revised the manuscript. All authors contributed to the acquisition 
and interpretations of data, and gave final approval and agree to be accountable for all aspects of work ensuring integrity and accuracy.

Competing interests None declared.

Patient consent Obtained.

Ethics approval The Troms $\emptyset$ Study has been approved by the Regional Committee of Medical and Health Research Ethics (REC North) (approval number 2015/1778) and the Norwegian Data Protection Authority, and performed in accordance with the 1964 Helsinki Declaration and its later amendments.

Provenance and peer review Not commissioned; externally peer reviewed.

Data sharing statement The data that support the findings of this study are available from the Troms $\emptyset$ Study but restrictions apply to the availability of these data, which were used under licence for the current study, and so are not publicly available. Data are however available from the authors upon reasonable request and with permission of the Tromsø Study.

Open Access This is an Open Access article distributed in accordance with the Creative Commons Attribution Non Commercial (CC BY-NC 4.0) license, which permits others to distribute, remix, adapt, build upon this work non-commercially, and license their derivative works on different terms, provided the original work is properly cited and the use is non-commercial. See: http://creativecommons.org/ licenses/by-nc/4.0/

(c) Article author(s) (or their employer(s) unless otherwise stated in the text of the article) 2018. All rights reserved. No commercial use is permitted unless otherwise expressly granted.

\section{REFERENCES}

1. Chow CK, Jolly S, Rao-Melacini P, et al. Association of diet, exercise, and smoking modification with risk of early cardiovascular events after acute coronary syndromes. Circulation 2010;121:750-8.

2. Kotseva K, Wood D, De Bacquer D, et al. EUROASPIRE IV: A European Society of Cardiology survey on the lifestyle, risk factor and therapeutic management of coronary patients from 24 European countries. Eur J Prev Cardiol 2016;23:636-48.

3. Statistics Norway. In-hosptial patients. 2017 https://www.ssb.no/ helse/statistikker/pasient (accessed 01 Jun 2017)

4. Mannsverk J, Wilsgaard T, Njølstad I, et al. Age and gender differences in incidence and case fatality trends for myocardial infarction: a 30-year follow-up. The Tromso Study. Eur J Prev Cardiol 2012;19:927-34.

5. The Norwegian myocardial infarction register report, 2015. https:// www.kvalitetsregistre.no/sites/default/files/2_arsrapport_2015 hjerteinfarkt.pdf (accessed 01 Jun 2017).

6. Murray CJ, Vos T, Lozano R, et al. Disability-adjusted life years (DALYs) for 291 diseases and injuries in 21 regions, 1990-2010: a systematic analysis for the Global Burden of Disease Study 2010. Lancet 2012;380:2197-223.

7. Jortveit J, Govatsmark RES, Digre TA, et al. Hjerteinfarkt i Norge i 2013. Tidsskrift for Den norske legeforening 2014;134:1841-6.

8. Cheng K, Ingram N, Keenan J, et al. Evidence of poor adherence to secondary prevention after acute coronary syndromes: possible remedies through the application of new technologies. Open Heart 2015;2:e000166.

9. Thakkar JB, Chow CK. Adherence to secondary prevention therapies in acute coronary syndrome. Med J Aust 2014;201:106-9.

10. Sandesara PB, Lambert CT, Gordon NF, et al. Cardiac rehabilitation and risk reduction: time to "rebrand and reinvigorate". J Am Coll Cardiol 2015;65:389-95.

11. Piepoli MF, Corrà U, Dendale $P$, et al. Challenges in secondary prevention after acute myocardial infarction: a call for action. Eur $J$ Prev Cardiol 2016;23:1994-2006.
12. Turnbull F, Woodward M, Neal B, et al. Do men and women respond differently to blood pressure-lowering treatment? Results of prospectively designed overviews of randomized trials. Eur Heart $J$ 2008;29:2669-80.

13. Hambraeus $K$, Tydén $P$, Lindahl $B$. Time trends and gender differences in prevention guideline adherence and outcome after myocardial infarction: data from the SWEDEHEART registry. Eur $J$ Prev Cardiol 2016;23:340-8.

14. Mannsverk J, Wilsgaard T, Mathiesen EB, et al. Trends in modifiable risk factors are associated with declining incidence of hospitalized and nonhospitalized acute coronary heart disease in a population. Circulation 2016;133:74-81.

15. Pyörälä K, De Backer G, Graham I, et al. Prevention of coronary heart disease in clinical practice. Recommendations of the task force of the European Society of Cardiology, European Atherosclerosis Society and European Society of Hypertension. Eur Heart $J$ 1994;15:121-61.

16. Wood D, Backer GD, Faergeman O, et al. Prevention of coronary heart disease in clinical practice. Recommendations of the second joint task force of European and other Societies on coronary prevention. Eur Heart J 1998;19:1434-503.

17. De Backer G, Ambrosioni E, Borch-Johnsen K, et al. European guidelines on cardiovascular disease prevention in clinical practice: third joint task force of European and other societies on cardiovascular disease prevention in clinical practice (constituted by representatives of eight societies and by invited experts). Eur J Cardiovascu Prevent Rehab 2003;10:S1-S10.

18. Graham I, Atar D, Borch-Johnsen K, et al. Fourth joint task force of the European Society of Cardiology and other Societies on Cardiovascular Disease Prevention in Clinical Practice. Eur J Cardiovasc Prevent Rehab 2007;14:S1.

19. Perk J, De Backer G, Gohlke H, et al. European Guidelines on cardiovascular disease prevention in clinical practice. Eur Heart $J$ 2012;33:1635-701

20. Piepoli MF, Hoes AW, Agewall S, et al. European guidelines on cardiovascular disease prevention in clinical practice. The sixth joint task force of the European Society of Cardiology and Other Societies on Cardiovascular Disease Prevention in Clinical Practice Developed with the special contribution of the European Association for Cardiovascular Prevention \& Rehabilitation (EACPR). Eur Heart J 2016;2016:2315-81.

21. Kotseva K, Wood D, De Backer G, et al. EUROASPIRE III: a survey on the lifestyle, risk factors and use of cardioprotective drug therapies in coronary patients from 22 European countries. Eur $J$ Cardiovasc Prev Rehabil 2009;16:121-37.

22. Stock EO, Redberg R. Cardiovascular disease in women. Curr Probl Cardiol 2012;37:450-526.

23. Cooney MT, Kotseva K, Dudina A, et al. Determinants of risk factor control in subjects with coronary heart disease: a report from the EUROASPIRE III investigators. Eur J Prev Cardiol 2013;20:686-91.

24. Bugiardini R, Yan AT, Yan RT, et al. Factors influencing underutilization of evidence-based therapies in women. Eur Heart $J$ 2011;32:1337-44.

25. Bangalore S, Fonarow GC, Peterson ED, et al. Age and gender differences in quality of care and outcomes for patients with ST-segment elevation myocardial infarction. Am J Med 2012;125:1000-9.

26. Akincigil A, Bowblis JR, Levin C, et al. Long-term adherence to evidence based secondary prevention therapies after acute myocardial infarction. J Gen Intern Med 2008;23:115-21.

27. Wei L, Flynn R, Murray GD, et al. Use and adherence to betablockers for secondary prevention of myocardial infarction: who is not getting the treatment? Pharmacoepidemiol Drug Saf 2004;13:761-6.

28. Jokhadar M, Wenger NK. Review of the treatment of acute coronary syndrome in elderly patients. Clin Interv Aging 2009;4:435-44. 